\title{
How cold was Europe at the Last Glacial Maximum? A synthesis of the progress achieved since the first PMIP model-data comparison
}

\author{
G. Ramstein ${ }^{1}$, M. Kageyama ${ }^{1}$, J. Guiot ${ }^{2}$, H. Wu ${ }^{2,3}$, C. Hély ${ }^{2}$, G. Krinner ${ }^{4}$, and S. Brewer ${ }^{2}$ \\ ${ }^{1}$ Laboratoire des Sciences du Climat et de l'Environnement, UMR CEA-CNRS-UVSQ 1572, CE Saclay, L'Orme des \\ Merisiers, Bât. 701, 91191 Gif-sur-Yvette Cedex, France \\ ${ }^{2}$ CEREGE, BP 80 Europole Méditerranéen de l'Arbois, 13545 Aix-en-Provence cedex 4, France \\ ${ }^{3}$ SKLLQ, Institute of Earth Environment, Chinese Academy of Sciences, Xi' an 710075, China \\ ${ }^{4}$ Laboratoire de Glaciologie et Géophysique de l'Environnement, 54, rue Molière, 38402 Saint Martin d'Hères cedex, France
}

Received: 1 December 2006 - Published in Clim. Past Discuss.: 22 January 2007

Revised: 3 May 2007 - Accepted: 31 May 2007 - Published: 18 June 2007

\begin{abstract}
The Last Glacial Maximum has been one of the first foci of the Paleoclimate Modelling Intercomparison Project (PMIP). During its first phase, the results of 17 atmosphere general circulation models were compared to paleoclimate reconstructions. One of the largest discrepancies in the simulations was the systematic underestimation, by at least $10^{\circ} \mathrm{C}$, of the winter cooling over Europe and the Mediterranean region observed in the pollen-based reconstructions. In this paper, we investigate the progress achieved to reduce this inconsistency through a large modelling effort and improved temperature reconstructions. We show that increased model spatial resolution does not significantly increase the simulated LGM winter cooling. Further, neither the inclusion of a vegetation cover compatible with the LGM climate, nor the interactions with the oceans simulated by the atmosphere-ocean general circulation models run in the second phase of PMIP result in a better agreement between models and data. Accounting for changes in interannual variability in the interpretation of the pollen data does not result in a reduction of the reconstructed cooling. The largest recent improvement in the model-data comparison has instead arisen from a new climate reconstruction based on inverse vegetation modelling, which explicitly accounts for the $\mathrm{CO}_{2}$ decrease at LGM and which substantially reduces the LGM winter cooling reconstructed from pollen assemblages. As a result, the simulated and observed LGM winter cooling over Western Europe and the Mediterranean area are now in much better agreement.
\end{abstract}

Correspondence to: M. Kageyama

(masa.kageyama@1sce.ipsl.fr)

\section{Introduction}

The aim of the first phase of the Paleoclimate Modelling Intercomparison Projet (hereafter PMIP1) was to assess the sensitivity of the atmosphere general circulation models (AGCMs) used to predict future climate change, to very different conditions. The Last Glacial Maximum, which occurred 21000 years ago, was chosen as a test for extremely cold conditions. For this period, a relatively large number of paleoclimate reconstructions exist, against which model results can be compared. For example, across Europe and western Siberia, models and reconstructions could be compared in terms of changes in Mean Annual Temperature (MAT), Mean Temperature of the Coldest Month (MTCO), total annual precipitation (TAP) and moisture index (ratio of the mean annual actual evaporation to the mean annual potential evaporation). These bioclimatic parameters were computed from pollen assemblages using a transfer function relating modern distributions of Plant Functional Types with climatic data (Peyron et al., 1998; Tarasov et al., 1999). For instance, the modern analogues found for the Western Europe pollen assemblages in the original climatic reconstructions from Peyron et al. (1998) were located in tundra or very cold steppe environments, which resulted in very cold MTCO reconstructions.

In order to involve a large number of groups and models that had not been previously used with paleoclimates, the LGM experimental design in PMIP1 was designed to be as simple as possible (Joussaume and Taylor (1995) and http://pmip.lsce.ipsl.fr/). The boundary conditions were as follows: the $\mathrm{CO}_{2}$ atmospheric concentration was fixed at $200 \mathrm{ppm}$ following the Vostok measurements (Raynaud et al., 1993) and the orbital parameters were set to their $21 \mathrm{ky} \mathrm{BP}$

Published by Copernicus Publications on behalf of the European Geosciences Union. 


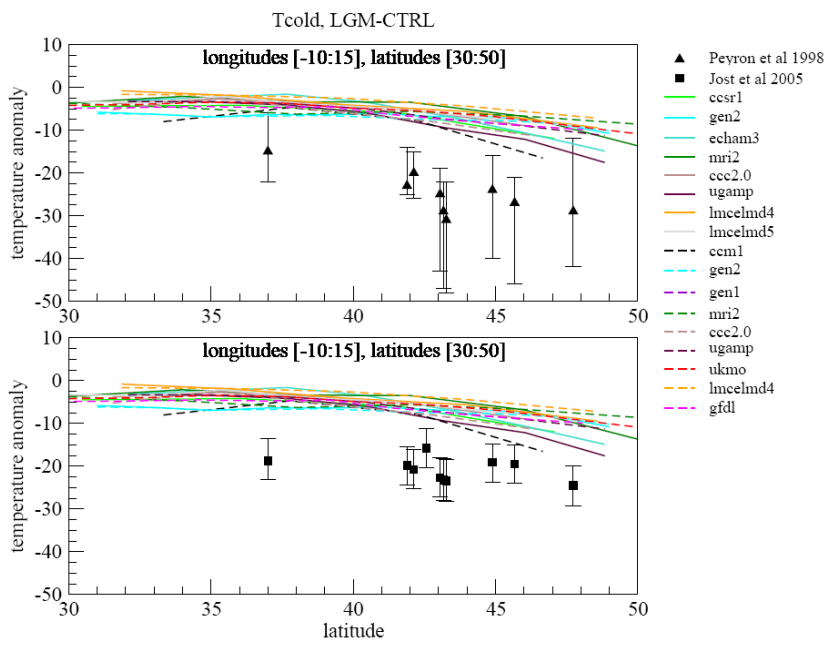

Fig. 1. (a) MTCO anomalies between the LGM and CTRL results for the PMIP1 models, compared to the MTCO anomalies (triangles $+90 \%$ confidence intervals) reconstructed from pollen as described in Peyron et al. (1998). (b) Same MTCO anomalies but the data set has been updated as described in Jost et al. (2005) (squares $+90 \%$ confidence intervals).

values (Berger, 1978); the ice-sheet elevation and extension, as well as the land-sea mask were prescribed using the ICE$4 \mathrm{G}$ reconstruction (Peltier, 1994); eight simulations used prescribed Sea Surface Temperature (SST) and sea-ice extension derived from CLIMAP (1981), while the eight others used a slab-ocean model to compute SST and sea-ice cover.

The comparison between these model results and pollenbased reconstructions over Europe and western Siberia showed a relatively good agreement for MAT, but large discrepancies were found over western Europe and the Mediterranean area for MTCO and TAP (Kageyama et al., 2001). Since then, the modern data base used for the calibration of the Peyron et al. (1998) and Tarasov et al. (1999) transfer function method has been updated (Peyron et al., 2005) and new reconstructions for western Europe and the Mediterranean area are slightly warmer (Jost et al., 2005). However, a comparison of the PMIP1 model results with this updated MTCO reconstruction (Fig. 1) shows that the modeldata disagreement remains, even if one takes into account the large error bars due to a poorly diversified vegetation (steppe-tundra) and a tolerance of this type of vegetation to large climatic amplitudes. This therefore raised a series of questions from models and data point of view. In the present paper, we first review different model improvements: using a higher spatial resolution, investigating the role of missing interactions or feedbacks, such as from the biosphere and the ocean. We then investigate factors that were not included in the first pollen-based reconstructions: the potential impact of a different interannual variability and that of a much lower $\mathrm{CO}_{2}$ at LGM, via the use of an Inverse Vegetation Model.

\section{Increasing the spatial resolution of the models}

Paleoclimatic reconstructions such as those based on pollen are representative of a small area around the sites where they have been retrieved, compared to the usual resolution (i.e. a few hundred km) of the AGCM used in PMIP1. Therefore, the spatial resolution of the PMIP models may be a problem when comparing model results to data, particularly in areas of complex coastlines and topography such as southern Europe and around the Mediterranean Basin. For sites situated in or close to mountain ranges such as the Pyrenees and the Alps, the local climate can be very different from the climate simulated in the corresponding grid box of the models. During the LGM, these mountain ranges were partly covered by large glaciers, which can affect the local atmospheric circulation but are not represented in the GCMs. Increasing the models' resolution should improve the representation of a given climate. However, it is unclear that the sensitivity of the models to changes in their boundary conditions will be affected by changing their resolution.

This question has been investigated by comparing the simulations of three AGCMs at low and high resolution (Jost et al., 2005), with the increase in resolution achieved through three different methods. All simulations were run according to the PMIP1 protocol. CCSR1 provided a run with a global T106 resolution (low resolution: T21), whereas the HadRM was nested within the HadAM global AGCM over a domain including the North Atlantic and Europe, and LMDZ used a stretched grid version, with higher resolution over Europe (low resolution: 72 points in longitude $\times 46$ points in latitude, high resolution $144 \times 108$, the resolution reaching $60 \mathrm{~km}$ over Paris). The CCSR and LMDZ experiments are all 11-year long, the last 10 years being used to compute the climatological averages. The HadAM and HadRM results are averages for the last 6 years of a 14-year-long presentday simulation and of the last 5 years of a 9-year-long LGM simulation. All these models have a spatial resolution of around 50-100 km over Europe. However in terms of MTCO (Fig. 2), there is not any convincing improvement for CCSR1 and LMDZ, while HadRM simulates cooler winter temperatures than the low resolution model, in better agreement with the reconstructions. However, the latter model simulates significant increases in precipitation over western Europe and the Mediterranean areas which are in total disagreement with the reconstructions. Therefore, Jost et al. (2005) argue that such increases in spatial resolution cannot explain the model - data MTCO discrepancy over Western Europe and the Mediterranean area. It remains to be investigated whether a larger increase in the resolution and the inclusion of finer scale processes in the models would better resolve the circulation and climate around the fine topography/coastlines of the European and Mediterranean areas and yield a better agreement of the model results with MTCO reconstructions. Other methods, such as statistical downscaling, could also be investigated. 


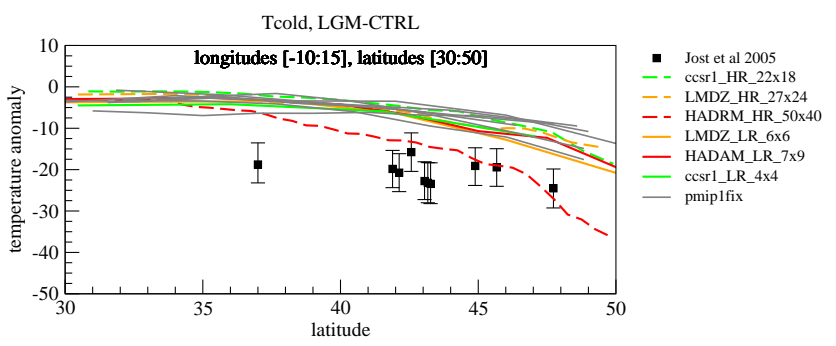

Fig. 2. MTCO LGM-CTRL anomalies for high resolution models, compared to their low resolution counterparts and to the Jost et al. (2005) reconstructions (squares $+90 \%$ confidence intervals). The results from the PMIP1 prescribed SST experiments are shown in grey for comparison. The number of points in longitude and latitude for the region of interest $\left(10^{\circ} \mathrm{W}-15^{\circ} \mathrm{E}, 30^{\circ} \mathrm{N}-50^{\circ} \mathrm{N}\right)$ is reported next to each model name.

\section{Increasing the number of components of the climate system taken into account in the models}

The AGCMs used in the first experiment require a set of accurate surface conditions. For the oceanic conditions, as explained in the introduction, the CLIMAP (1981) data set was chosen. For the biosphere, to simplify the PMIP1 experimental design, no change was made, except the inclusion of new continental grid points due to the LGM sea-level drop. The characteristics of these grid points were obtained by averaging those of neighbouring land points. For other periods, the model - data comparison has been improved by taking into account additional components in the models. For example, for the simulation of the onset of the last glaciation $115 \mathrm{kyr}$ ago, it has been shown that taking vegetation changes into account (e.g. de Noblet et al., 2006) largely amplifies the cooling related to the Northern Hemisphere decrease in summer insolation. Khodri et al. (2001) demonstrated that atmosphere and ocean feedbacks on the water cycle favoured the accumulation of snow in the northern high latitudes, by including ocean interactions in the experimental design via the use of a coupled atmosphere-ocean GCM. For the Mid Holocene the extension of African monsoon to the North is in better agreement with the data when ocean and biosphere feedbacks are included (Braconnot et al., 2000).

\subsection{Investigating the role of the biosphere}

The PMIP1 LGM experiments all used present vegetation cover. South of the Fennoscandian ice-sheet, the albedo may have been underestimated at locations where forest is present today. In European regions presently dominated by agriculture, the difference between prescribing the present vegetation and the LGM one (steppe, tundra) may not be very large in terms of climate, since these surfaces are not very different in terms of albedo or roughness length. Several studies have investigated the impact of an LGM vegetation on a simulated LGM climate (Crowley and Baum, 1997; Kubatzki and

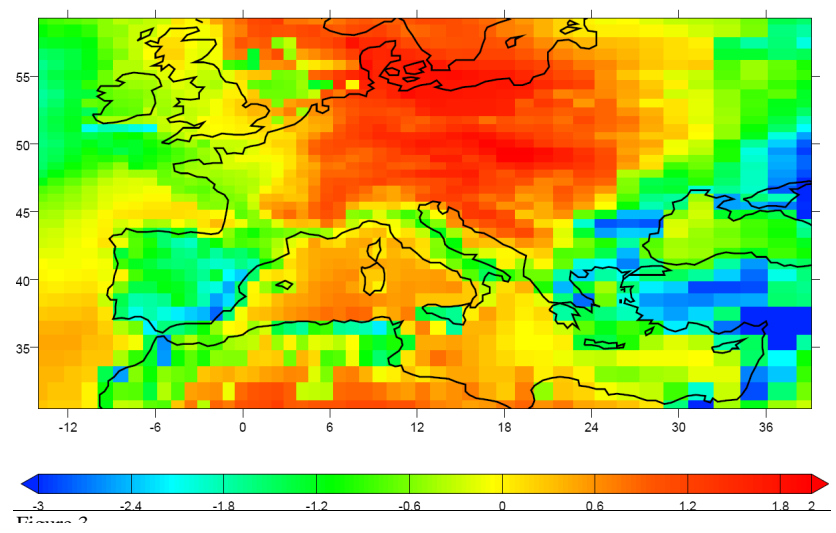

Fig. 3. MTCO anomalies between an LGM simulation run with PMIP boundary conditions (no change in vegetation) and an LGM simulation where the vegetation is computed by asynchronous coupling with the Dynamical Global Vegetation Model ORCHIDEE. Both these simulations have been performed with the LMDZ model with a stretched grid over Europe, in the version of Jost et al. (2005).

Claussen, 1998; Levis et al., 1999; Wyputta and McAvaney, 2001; Crucifix and Hewitt, 2005). This impact has been evaluated either with respect to present climate simulations using the actual or pre-industrial vegetation or to simulations using present potential vegetation. While the impact of prescribing or interactively computing LGM vegetation can be large in regions like Siberia, none of these studies shows a large impact (more than a few ${ }^{\circ} \mathrm{C}$ ) on European temperatures. However, results are not often given in terms of MTCO, but most often as Mean Annual Temperatures.

Here, to investigate the possible impact of using present vegetation in an LGM climate simulation, we have computed the LGM vegetation cover associated with the high resolution LGM climate obtained with LMDZ described in the previous section, using the ORCHIDEE Dynamic Global Vegetation Model (Krinner et al., 2005). This DGVM describes vegetation in terms of natural vegetation (competition between 10 Plant Functional Types) and agriculture (2 vegetation types) + bare soil. All vegetation types can co-exist in each model grid box and the vegetation is described as the fraction occupied by each vegetation type. The results show that the LGM over western Europe is characterised by a poor vegetation cover, dominated by grasses rather than forests (Kageyama et al., 2005). We have then imposed the simulated LGM vegetation in a new run of the LMDZ model, still at high resolution over Europe. The results are shown on Fig. 3 as MTCO anomalies. The impact of vegetation results in a cooling of 1 to $2^{\circ} \mathrm{C}$ for MTCO in the Iberian peninsula, of around $1^{\circ} \mathrm{C}$ on the Adriatic side of the Italian Peninsula, of around $0.5^{\circ} \mathrm{C}$ on the French Atlantic and Mediterranean coasts, and of 1 to $3^{\circ} \mathrm{C}$ over the Greek peninsula and the Near-East. The rest of France and Central Europe, down to the Adriatic coast, experience a warming of 1 to $2^{\circ} \mathrm{C}$ as a result of these changes 


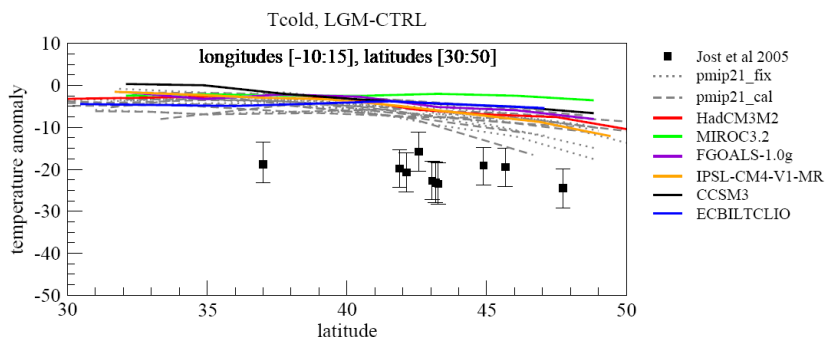

Fig. 4. MTCO anomalies between LGM and CTRL for the coupled OA GCM involved in PMIP2, compared to the Jost et al. (2005) pollen-based reconstructions (squares $+90 \%$ confidence intervals). The PMIP1 model results from Fig. 1 are shown in grey for easier comparison.

in vegetation cover. These vegetation changes therefore do not overcome the model/data discrepancy but do slightly improve the model results over areas such as southern France and the Iberian Peninsula. The region of simulated cooling is limited, showing that a vegetation compatible with the LGM climate does not act to systematically cool winter temperatures for the Last Glacial Maximum climate. For instance, including an LGM vegetation induces a warming between the Black and Caspian Seas (Fig. 3).

\subsection{Investigating the role of the ocean}

Several studies have shown that the CLIMAP SST and seaice cover data set needed to be improved and new estimates have recently been made available (e.g. through the MARGO project, Kucera et al., 2005). In addition, simulations obtained using different SST and sea-ice cover estimates for the LGM have also helped in the quantification of the impact of possible errors in CLIMAP (Pinot et al., 1999). However, to avoid the problems related to prescribing SSTs at the global scale, a major effort has been achieved by several groups in the recent years to produce coupled atmosphere-ocean GCM simulations of the LGM climate. After some pioneering simulations (e.g. Hewitt et al., 2001; Kitoh et al., 2001; Peltier and Solheim, 2004), experiments were recently run within the PMIP2 exercise (Paleoclimate Modelling Intercomparison Project, 2nd phase, Harrison et al., 2002; Braconnot et al., 2007a, b, http://pmip2.lsce.ipsl.fr). For this exercise, atmosphere-ocean GCM (AOGCM) simulations have been performed using 1) the $21 \mathrm{ky} \mathrm{BP}$ insolation (Berger, 1978) 2) a decrease in the atmospheric $\mathrm{CO}_{2}$ concentration revaluated to 185 ppm (Monnin et al., 2001) and 3) the new global ice sheet reconstruction (ICE-5G) from Peltier (2004). The spectrum of ocean dynamics responses is quite large (Weber et al., 2006). The North Atlantic SST and sea ice extent changes simulated by these coupled ocean-atmosphere models are also different from model to model, but all models show a strengthening of the mid-latitude meridional temperature gradient, a feature which is clear from the MARGO data (for more detail, see Kageyama et al., 2006). On the other hand, none of the PMIP2 models simulates a maximum seaice extent as large as CLIMAP (1981), and the LGM-CTRL SST anomaly simulated over the North Atlantic is generally smaller than the CLIMAP (1981) reconstruction used in the PMIP1 prescribed SST experiments. The new LGM North Atlantic conditions are therefore less likely than the initial CLIMAP (1981) conditions to produce significantly colder MTCO over oceanic western Europe. However, Fig. 4 shows that the discrepancy between model and data over western Europe and Mediterranean Basin is unchanged for PMIP1 and PMIP2 models. The MTCO simulated by the PMIP2 models tend to be warmer, but are within the range of the results from the PMIP1 models, despite the warmer North Atlantic SSTs and reduced sea-ice extent. This result demonstrates the rather weak sensitivity of the simulated MTCO to large differences in LGM SST produced by the models involved in PMIP2, which is quite unexpected.

\section{Investigating the impact of a different climate vari- ability on vegetation}

Most PMIP model results have been analysed in terms of changes in the mean climate, defined as the average of climatic variables such as MTCO on around 15 years of simulation (for PMIP1, 50-100 years for PMIP2). Results from proxy-based reconstructions for the LGM have also been interpreted as changes in the mean climate as these proxies are calibrated against the modern climatology. The assumption has therefore been that interannual variability does not vary. However, Kageyama et al. (2006) have shown that in fact, the interannual variability in MTCO changes in the LGM simulations, compared to the CTRL ones. Most PMIP2 models simulate an increase in the amplitude of interannual MTCO variability, suggesting the occurrence of much cooler extreme episodes than if we assume a constant interannual variability. This could have an impact on the vegetation which is not taken into account in the current interpretation of pollen data.

We have therefore performed preliminary sensitivity experiments to investigate under which conditions an agreement with the pollen data can be obtained. In particular, we have tested whether changes in interannual variability alone could lead to significant changes in vegetation. We have used the Lund-Potsdam-Jena Dynamic Global Vegetation Model (LPJ DGVM, Sitch et al., 2003), run offline under different $\mathrm{CO}_{2}$ and climatic forcings. For these preliminary experiments, the climate inputs (averages and variability) were computed from the anomalies extracted from the IPSL_CM4 model PMIP2 simulations. These anomalies were then added to the Climatic Research Unit (CRU) observations (Mitchell et al., 2004). The DVGM was run for 4 sites in the Mediterranean Basin. A fifth site (La Grande Pile), located to the north of these sites, was included as a 
control site representative of the European continental climate. These sites are well documented and dated for the LGM period, have been used in several previous studies (Peyron et al., 1998; Jost et al., 2005) and are included in the comparisons shown in the rest of the present work. The output of the model is given as leaf area index (LAI) for each plant functional type (Fig. 5).

The results form part of a larger project testing various combinations of changes in climate variability on vegetation composition and dynamics. To facilitate the interpretation of the results, only the most relevant results for the LGM are shown here. As a control, the model was run under present climate and $\mathrm{CO}_{2}$ concentration (experiment 1 ). In this experiment the model mostly simulates forests, which is in agreement with modern vegetation composition (coniferous forests such as Abies or Picea forests in La Grande Pile in the Vosges region, and modern Mediterranean forests dominated by temperate broadleaved evergreen species such as evergreen Quercus species in the other four sites). We then tested conditions under which the steppe-tundra observed during the LGM are obtained.

In the second experiment, we test the effect of changing the $\mathrm{CO}_{2}$ concentration to LGM levels $(200 \mathrm{ppm})$, with no change in the climate. The reduction in $\mathrm{CO}_{2}$ has been shown to have an important impact on LGM vegetation (Jolly and Haxeltine, 1997; Wu et al., 2007). The LPJ model shows that the LGM CO 2 value results in a reduction of LAI but does not significantly affect the vegetation composition.

In the following experiments, the $\mathrm{CO}_{2}$ concentration is kept at its LGM value. The third scenario is a test of the change in interannual variability. If the vegetation composition is more sensitive to extreme cold events than changes in mean temperature, an increase in temperature variability could result in an increase of steppe or tundra vegetation, as they resist very low minimum temperatures. In a series of experiments, we have kept the mean climatology at modern values, but have increased the modern temperature variability by a factor ranging from 1 to 3 , resulting in a amplification of the climatic extremes. Figure 5 shows the results of the last of these experiments, in which the temperature variability has been increased by a factor of 3 . While this results in a shift to a boreal vegetation type at three of the five sites, neither steppe nor tundra becomes dominant.

We then tested whether changes in mean climate parameters, with no variability change, result in a simulated dominant steppe-tundra vegetation. We tested the effect of mean monthly temperature anomalies (MTA), by increasing the temperature anomaly simulated by IPSL_CM4 by a factor varying between 0.5 and 3 . At the Grande Pile, increasing the amplitude of the MTA anomaly up to 1.25 results in an increase in grass production, and the vegetation becomes dominated by grasslands at 1.25 . Above this value, no more vegetation is simulated at this site, and we have therefore discarded the results from runs using higher factors. The vegetation simulated at the four Mediterranean sites shows

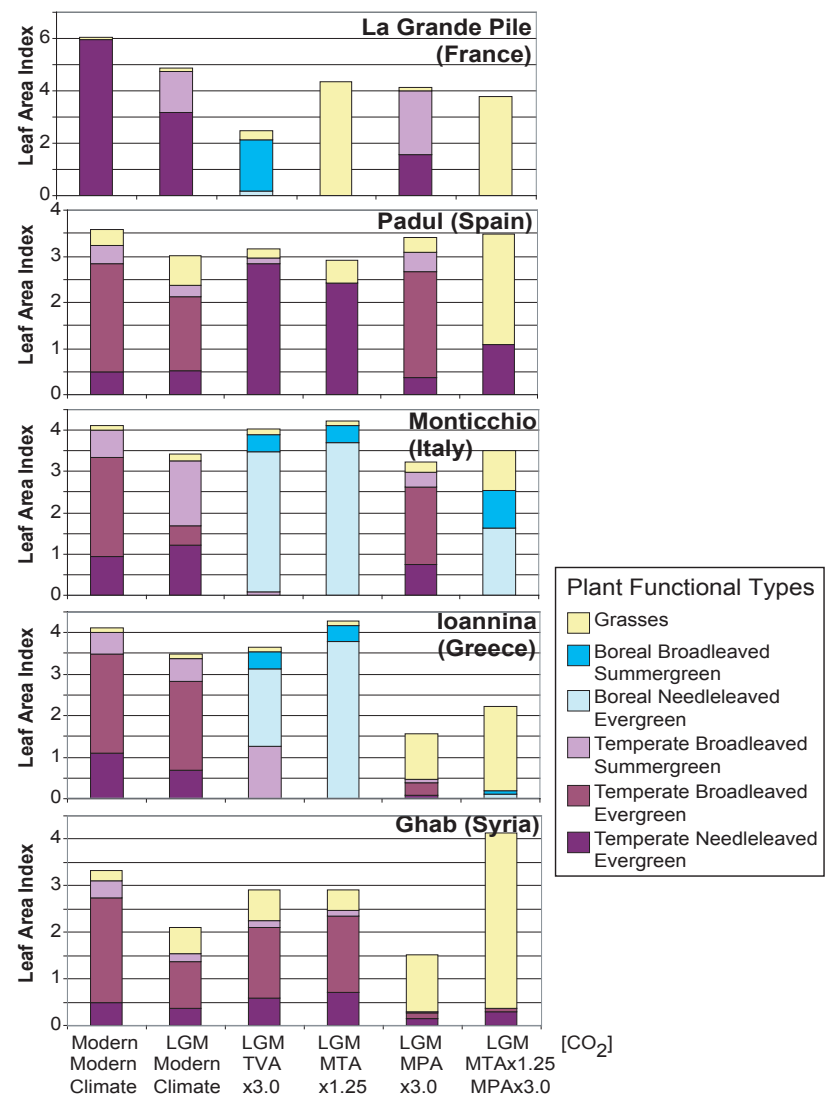

Fig. 5. Vegetation composition simulated for five European sites (La Grande Pile $\left(47.73^{\circ} \mathrm{N}, 6.50^{\circ} \mathrm{E}\right)$, Padul $\left(37.0^{\circ} \mathrm{N}, 3.67^{\circ} \mathrm{E}\right)$, Monticchio $\left(40.94^{\circ} \mathrm{N}, 15.60^{\circ} \mathrm{E}\right)$, Ioannina $\left(39.76^{\circ} \mathrm{N}, 20.73^{\circ} \mathrm{E}\right)$, and Ghab $\left(35.68^{\circ} \mathrm{N}, 35.30^{\circ} \mathrm{E}\right)$ ), on which we have applied six different scenarios: 1) Modern $\mathrm{CO}_{2}(345 \mathrm{ppm})$ and modern climate (i.e. modern climatological average and variability as described by the CRU dataset), 2) LGM CO 2 (200 ppm) and modern climate, 3) $\mathrm{LGM} \mathrm{CO}_{2}$ and modern climate but Temperature Variability Anomaly (TVA) increased by a factor of 3,4$) \mathrm{LGM} \mathrm{CO}_{2}$ and modern climate but Mean Temperature Anomaly (MTA) increased by a factor of $1.25,5) \mathrm{LGM} \mathrm{CO}_{2}$ and modern climate but Mean Precipitation Anomaly (MPA) increased by a factor of 3 , and finally 6) $\mathrm{LGM} \mathrm{CO}_{2}$ and combined $1.25 \times$ MTA with $3.0 \times$ MPA.

a shift to a cooler vegetation type, similar to that observed in experiment 3 with MTA anomalies increased by a factor of 1.25. We then retained these MTA anomalies and tested the effect of increasing TVA again, but no additional impact on the vegetation composition was observed (not shown). This indicates that once the change in MTA is taken into account, the change in TVA has no or only a negligible role in the simulated vegetation.

In parallel, we tested the effect of rainfall changes without changing temperature. As in experiments 3 and 4, a change in the imposed precipitation variability (PVA) has no effect on vegetation composition. In contrast, changes in mean monthly precipitation anomalies (MPA) result in dominant 


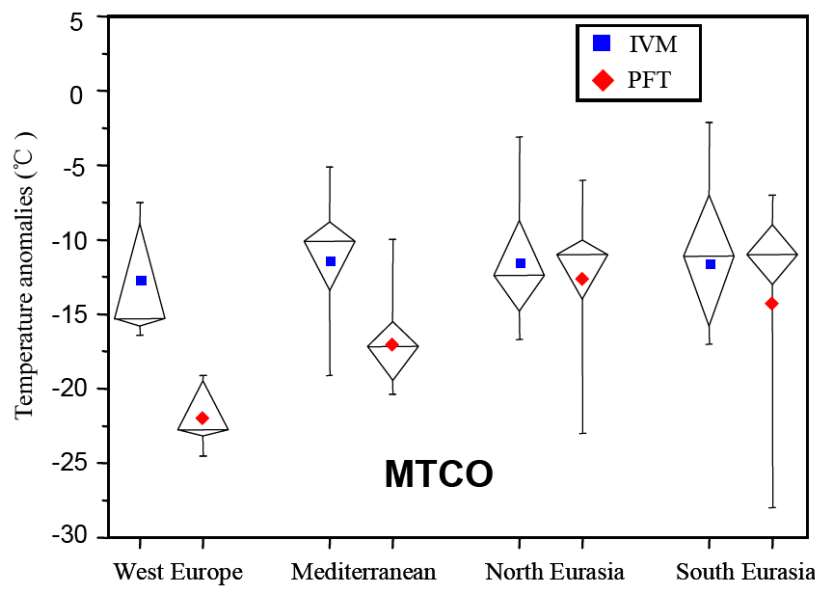

Fig. 6. Comparison of the MTCO reconstructions using the Plant Functional Type (Jost et al., 2005) and the Inverse Vegetation Modelling method (Wu et al., 2007). Boxes indicate the interquartile intervals (25th and 75th percentiles), and the bars are show the $90 \%$ intervals (5th and 95th percentiles). Horizontal bar in the boxes is the median, and the colored symbol is the mean value.

grassland at the Ioannina and Ghab sites, when MPA is reduced by a factor of 3 (Fig. 5, Experiment 5). In the last experiment, steppe-tundra vegetation occur in all sites when the simulated MTA values are reduced by a factor of 1.25 and combined with MPA values reduced by a factor of 3 .

In practice, this means that LGM temperatures would have been 5 to $10^{\circ} \mathrm{C}$ colder than those simulated by IPSL_CM4 in order to be consistent with a steppe-tundra vegetation. In addition, total precipitation values would have been 100 to $600 \mathrm{~mm} /$ year less than those simulated by IPSL_CM4. Without these changes in mean climate values, variability changes alone do not favour the growth of either steppe or tundra vegetation. Further, when these mean conditions are set, changing variability does not affect simulated vegetation composition.

\section{New temperature reconstructions using an inverse vegetation model}

The statistical reconstruction methods previously used (Peyron et al., 1998; Tarasov et al., 1999; Jost et al., 2005) are built upon the assumption that plant-climate interactions remain the same through time, and the fact that the calibration is done on modern data implicitly assumes that these interactions are independent of changes in atmospheric $\mathrm{CO}_{2}$. This assumption may lead to a considerable bias, as polar ice core records show that the atmospheric $\mathrm{CO}_{2}$ concentration was much lower in the LGM than in the present time (EPICA community members, 2004). Less carbon was then available for photosynthesis processes, and the effect of reduced $\mathrm{CO}_{2}$ levels is interpreted by statistical reconstructions methods directly as changes in one or more climatic parame-

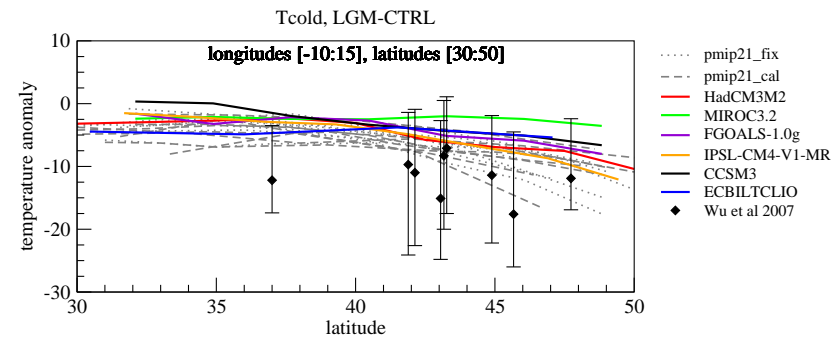

Fig. 7. MTCO anomalies as computed by PMIP1 and PMIP2 simulations compared to the new pollen-based reconstructions, using Inverse Vegetation Modelling (diamonds $+90 \%$ confidence intervals).

ters. At the same time, a number of palaeoecological studies (Jolly and Haxeltine, 1997; Street-Perrott et al., 1997; Cowling and Sykes, 1999) have shown that plant-climate interactions are sensitive to atmospheric $\mathrm{CO}_{2}$ concentration in the past, and that part of the observed changes may be attributed to changes in $\mathrm{CO}_{2}$ levels alone. The only solution to solve this problem is to use a vegetation model in an inverse mode, i.e. to calculate some model inputs (climate) when model outputs are constrained by the pollen data and the $\mathrm{CO}_{2}$ concentration is set to its correct value. This model inversion, which uses a Monte-Carlo-Markov-Chain algorithm to explore possible combinations of climate parameters, was applied to a few sites in Southern Europe by Guiot et al. (2000). The exploration of a large number of climate scenarios allows an assessment of the probability of different anomalies, and therefore the investigation of different possible combinations of climate parameters, that may result in similar vegetation. They showed that, whilst there remains a high probability of the same reduction in temperatures reconstructed by the statistical method (Peyron et al., 1998), there is an equal probability of an alternative warmer climate when the $\mathrm{CO}_{2}$ concentration is set to $200 \mathrm{ppmv}$. It was, however, not possible to chose between these two scenarios.

Recently Wu et al. (2007) have improved the method by better constraining the model output with pollen data and using a more recent version of the model (BIOME4, Kaplan et al., 2003). They applied this to the data used by Peyron et al. (1998), Tarasov et al. (1999) and Jost et al. (2005). Their results confirmed that several solutions were possible for the LGM climate in Western Europe where a mixture of steppes and tundra existed. As these biomes have no clear analogues today, reconstructions based on statistical methods will tend to choose the least poor match, or fail to find a match. In the dataset used by Peyron et al. (1998), these analogues were located in tundra or very cold steppes, resulting in very low reconstructed temperatures. In the improved dataset of Jost et al. (2005), the analogues selected were intermediate analogues in warmer steppes. In the inverse modelling results, Wu et al. (2007) showed that a significantly warmer climate was the most probable and that statistical methods overestimated the MTCO anomalies by about $10^{\circ} \mathrm{C}$, referring to a 
climate that has no modern analogue. They also showed that the uncertainties were also underestimated by the statistical methods, again due to lack of well-constrained modern analogues for the LGM vegetation. This is shown on Fig. 6, on which the results of both methods are compared in terms of the average result (symbol) and of the 5, 25, 50, 75 and 95\% percentiles of the possible MTCOs for four different regions. For western Europe and the Mediterranean areas, the confidence intervals obtained with the IVM method are much larger than those obtained via the PFT statistical method.

Comparisons of these new reconstructions with the models show that, as a result of these changes (warmer anomalies and increased confidence intervals), the majority of simulations, from the PMIP2 project but also from the atmospheric models of the PMIP1 project, are much closer to the reconstructed temperatures, generally within their $90 \%$ confidence interval. However, both the PMIP1 and PMIP2 results still fall in the warmer part of this confidence interval. In particular, the PMIP2 model results, generally warmer than the PMIP1 results, remain too warm compared to the best guess reconstructed value, by as much as $10^{\circ} \mathrm{C}$ for three of the sites, and by a few ${ }^{\circ} \mathrm{C}$ for the others.

\section{Conclusion and perspectives}

Thanks to the improved methodology based on inverse vegetation modelling (Wu et al., 2007), new estimates of the cooling over Western Europe at LGM are available. These estimates correspond to a reduced amount of cooling compared to previous reconstructions, mainly because of the progress achieved in accounting for the impact of lower $\mathrm{CO}_{2}$ concentration. These new reconstructions are also characterised by an increase in the associated error bars, in comparison to the previous ones, in better agreement with ecophysiology. Figure 7 shows both the most recent reconstructions and the new simulations from PMIP2. On this plot, most models are now in the upper part of the confidence interval of the MTCO reconstructions. The preliminary results presented in Sect. 4 show that to be consistent with the observed LGM vegetation over Europe and the Mediterranean Basin, the IPSL_CM4 model would need to be cooler by 5 to $10^{\circ} \mathrm{C}$. From Fig. 7 , we can see that this indeed would result in a better agreement with the new MTCO estimates for this model. The results obtained via the two vegetation models are therefore consistent. This will need to be confirmed by extending the analyses presented in Sect. 4 to the results of other PMIP2 models.

As we show in Sect. 3.1, the impact of vegetation on the simulated MTCO is not homogeneous over Western Europe. In some regions, for example the Iberian Peninsula, this could account for some of the remaining difference between the simulations and the reconstructions. The new AOV GCM simulations may therefore give a better agreement with the new reconstructions.
In this work, we have focused on one variable for which the model-data discrepancies was very large: the temperature of the coldest month. This work will be followed by the analysis of another large model-data discrepancy: the representation of the total annual precipitation. The first PMIP modeldata comparison showed an important underestimation of the drying over western Europe and the Mediterranean Basin. This result will be re-evaluated in the light of new model simulations and new reconstructions as has been proposed here for the temperature of the coldest month. The next steps in modelling the Last Glacial Maximum climate will be to use fully coupled atmosphere-ocean-vegetation models, and then to include representations of the oxygen isotopes and marine and terrestrial carbon cycles. This will constitute a comprehensive and consistent approach towards a better understanding of the reconstructions.

Acknowledgements. The authors thank the PMIP participants for providing their data and J.-Y. Peterschmitt for the management of the PMIP data base and his precious help with the graphics. The results from the PMIP2 project use the PMIP2 database from November 2006. This work was partly funded by the MOTIF European Project and the French ANR IDEGLACE project. The authors also wish to thank the two anonymous reviewers and the editors for their helpful comments.

Edited by: N. Weber

\section{References}

Berger, A.: Long-term variations of caloric insolation resulting from the earth's orbital elements, Quat. Res., 9, 139-167, 1978.

Braconnot, P., Marti, O., Joussaume, S., and Leclainche, Y.: Ocean feedback in response to $6 \mathrm{kyr}$ BP insolation, J. Climate, 13, 1537-1553, 2000.

Braconnot, P., Otto-Bliesner, B., Harrison, S., Joussaume, S., Peterchmitt, J.-Y., Abe-Ouchi, A., Crucifix, M., Fichefet, T., Hewitt, C. D., Kageyama, M., Kitoh, A., Loutre, M.-F., Marti, O., Merkel, U., Ramstein, G., Valdes, P., Weber, S. L., Yu, Y., and Zhao, Y.: Results of PMIP2 coupled simulations of the MidHolocene and Last Glacial Maximum - Part 1: experiments and large-scale features, Clim. Past, 3, 261-277, $2007 \mathrm{a}$.

Braconnot, P., Otto-Bliesner, B., Harrison, S., Joussaume, S., Peterchmitt, J.-Y., Abe-Ouchi, A., Crucifix, M., Fichefet, T., Hewitt, C. D., Kageyama, M., Kitoh, A., Loutre, M.-F., Marti, O., Merkel, U., Ramstein, G., Valdes, P., Weber, S. L., Yu, Y., and Zhao, Y.: Results of PMIP2 coupled simulations of the MidHolocene and Last Glacial Maximum - Part 2: feedbacks with emphasis on the location of the ITCZ and mid-and high latitudes heat budget, Clim. Past, 3, 279-296, 2007b.

CLIMAP: Seasonal reconstructions of the Earth's surface at the last glacial maximum in Map Series, Technical Report MC-36. Boulder, Colorado: Geological Society of America, 1981.

Cowling, S. A. and Sykes, M.: Physiological significance of low atmospheric $\mathrm{CO}_{2}$ for plant-climate interactions, Quat. Res., 52, 237-242, 1999. 
Crowley, T. and Baum, S.: Effect of vegetation on an ice-age climate model simulation, J. Geophys. Res., 102(D14), 16463 $16480,1997$.

Crucifix, M. and Hewitt, C. D.: Impact of vegetation changes on the dynamics of the atmosphere at the Last Glacial Maximum, Clim. Dyn., 25, 447-459, doi:10.1007/s00382-005-0013-8, 2005.

De Noblet, N., Prentice, I. C., Joussaume, S., Texier, D., Botta, A., and Haxeltine, A.: Possible role of atmosphere-biosphere interactions in triggering the last glaciation, Geophys. Res. Lett., 23, 3191-3194, 1996.

EPICA community members: Eight glacial cycles from an Antarctic ice core, Nature, 429, 623-628, 2004.

Guiot, J., Torre, F., Jolly, D., Peyron, O., Boreux, J.-J., and Cheddadi, R.: Inverse vegetation modeling by Monte Carlo sampling to reconstruct palaeoclimate under changed precipitation seasonality and $\mathrm{CO}_{2}$ conditions: application to glacial climate in Mediterranean region, Ecol. Model., 127, 119-140, 2000.

Harrison, S. P., Braconnot, P., Joussaume, S., Hewitt, C. D., and Stouffer, R. J.: Comparison of paleoclimate simulations enhances confidence in models, EOS, 83, 447, 2002.

Hewitt, C. D., Broccoli, A. J., Mitchell, J. F. B., and Stouffer, R. J.: A coupled model study of the last glacial maximum: was part of the North Atlantic relatively warm?, Geophys. Res. Lett., 28, 1571-1574, 2001.

Jolly, D. and Haxeltine, A.: Effect of low glacial atmospheric $\mathrm{CO}_{2}$ on tropical African montane vegetation, Science, 276, 786-788, 1997.

Jost, A., Lunt, D., Kageyama, M., Abe-Ouchi, A., Peyron, O., Valdes, P. J., Ramstein, G: High-resolution simulations of the last glacial maximum climate over Europe: a solution to discrepancies with continental palaeoclimatic reconstructions?, Clim. Dyn., 24, 577-590, 2005.

Joussaume, S. and Taylor, K. E.: Status of the Paleoclimate Modeling Intercomparison Project (PMIP), in: Proc. 1st Int AMIP Sci. Conf., Monterrey, California, USA, 15-19 May 1995, pp 425430, WCRP-92, 1995.

Kageyama, M., Combourieu Nebout, N., Sepulchre, P., Peyron, O., Krinner, G., Ramstein, G., and Cazet, J.-P.: The Last Glacial Maximum and Heinrich Event 1 in terms of climate and vegetation around the Alboran Sea: a preliminary model-data comparison, Compte Rendus Geoscience, 337, 983-992, 2005.

Kageyama, M., Laîné, A., Abe-Ouchi, A., Braconnot, P., Cortijo, E., Crucifix, M., de Vernal, A., Guiot, J., Hewitt, C. D., Kitoh, A., Kucera, M., Marti, O., Ohgaito, R., Otto-Bliesner, B., Peltier, W. R., Rosell-Melé, A., Vettoretti, G., Weber, S. L., Yu, Y., and MARGO Project members: Last Glacial Maximum temperatures over the North Atlantic, Europe and western Siberia: a comparison between PMIP models, MARGO sea-surface temperatures and pollen-based reconstructions, Quat. Sci. Rev., 25, 2082-2102, 2006.

Kageyama, M., Peyron, O., Pinot, S., Tarasov, P., Guiot, J., Joussaume, S., and Ramstein, G.: The Last Glacial Maximum climate over Europe and Western Siberia: a PMIP comparison between models and data, Clim. Dyn., 17, 23-43, 2001.

Kaplan, J. O., Bigelow, N. H., Bartlein, P. J., Christensen, T. R., Cramer, W., Harrison, S. P., Matveyeva, N. V., McGuire, A. D., Murray, D. F., Prentice, I. C., Razzhivin, V. Y., Smith, B., Walker, D. A., Anderson, P. M., Andreev, A. A., Brubaker, L. B., Edwards, M. E., Lozhkin, A. V., and Ritchie, J.: Climate change and Arctic ecosystems II: Modeling, palaeodata-model comparisons, and future projections, J. Geophys. Res.-Atmos., 108(D19), 8171, doi:10.1029/2002JD002559, 2003.

Khodri, M., Leclainche, Y., Ramstein, G., Braconnot, P., Marti, O., and Cortijo, E.: Simulating the amplification of orbital forcing by ocean feedbacks in the last glaciation, Nature, 410, 570-574, 2001.

Kim, S.-J., Flato, G. M., Boer, G. J., and McFarlane, N. A.: A coupled climate simulation of the Last Glacial Maximum, part 1: transient multi-decadal response, Clim. Dyn., 19, 520-537, 2002.

Kitoh, A., Murakami, S., and Koide, H.: A simulation of the Last Glacial Maximum with a coupled atmosphere-ocean GCM, Geophys. Res. Lett., 28, 2221-2224, 2001.

Kubatzki, C. and Claussen, M.: Simulation of the global biogeophysical interactions during the Last Glacial maximum, Clim. Dyn., 14, 461-471, 1998.

Krinner, G., Viovy, N., de Noblet-Ducoudré, N., Ogée, J., Polcher, J., Friedlingstein, P., Ciais, P., Sitch, S., and Prentice, I. C.: A dynamic global vegetation model for studies of the coupled atmosphere-biosphere system, Global Biogeochem. Cycles, 19, GB1015, doi:10.1029/003GB002199, 2005.

Kucera, M., Rosell-Melé, A., Schneider, R., Waelbroeck, C., and Weinelt, M.: Multiproxy approach for the reconstruction of the glacial ocean surface (MARGO), Quat. Sci. Rev., 24, 813-819, 2005.

Levis, S., Foley, J. A., and Pollard, D.: CO2, climate, and vegetation feedbacks at the Last Glacial Maximum, J. Geophys. Res. 104(D24), 31 191-31 198, 1999.

Monnin, A., Indermuhle, E., Dallenbach, A., Fluckiger, J., Stauffer, B., Stocker, D., Raynaud, T. F., and Barnola, J.-M.: Atmospheric $\mathrm{CO}_{2}$ concentrations over the last glacial termination, Science, 291, 112-114, 2001.

Peltier, W. R.: Ice age paleotopography, Science, 265, 195-189, 1994.

Peltier, W. R.: Global glacial isostasy and the surface of the ice-age Earth: the ICE-5G (VM2) model and GRACE, Ann. Rev. Earth Planet. Sci., 32, 111-149, 2004.

Peltier, W. R. and Solheim, L. P.: The climate of the Earth at Last Glacial Maximum: statistical equilibrium state and a mode of internal variability, Quat. Sci. Rev., 23, 335-357, 2004.

Peyron, O., Bégeot, C., Brewer, S., Heiri, O., Magny, M., Millet, L., Ruffaldi, P., Van Campo, E., and Yu, G.: Late-Glacial climatic changes in Eastern France (Lake Lautrey) from pollen, lake-levels, and chironomids, Quat. Res., 64, 197-211, 2005.

Peyron, O., Guiot, J., Cheddadi, R., Tarasov, P., Reille, M., de Beaulieu, J. L., Bottema, S., and Andrieu, V.: Climatic reconstruction in Europe for 18,000 yr B.P. from pollen data, Quat. Res., 49, 183-196, 1998.

Pinot, S., Ramstein, G., Marsiat, I., De Vernal, A., Peyron, O., Duplessy, J. C., and Weinelt, M.: Sensitivity of the European LGM climate to North Atlantic sea-surface temperature, Geophys. Res. Lett., 26, 1893-1896, 1999.

Raynaud, D., Jouzel, J., Barnola, J. M., Chappellaz, J., Delmas, R. J., and Lorius, C.: The ice record of greenhouse gases, Science, 259, 926-934, 1993.

Sitch, S., Smith, B., Prentice, I. C., Arneth, A., Bondeau, A., Cramer, W., Kaplan, J., Levis, S., Lucht, W., Sykes, M., Thonicke, K., and Venevski, S.: Evaluation of ecosystem dynam- 
ics, plant geography and terrestrial carbon cycling in the LPJ Dynamic Vegetation Model, Global Change Biol., 9, 161-185, 2003.

Street-Perrott, F. A., Huang, Y. S., Perrott, A., Eglinton, G., Barker, P., Khelifa, L. B., Harkness, D. D., and Olago, D. O.: Impact of lower atmospheric carbon dioxide on tropical mountain ecosystems, Science, 278, 1422-1426, 1997.

Tarasov, P. E., Peyron, O., Guiot, J., Brewer, S., Volkova, V. S., Bezusko, L. G., Dorofeyuk, N. I., Kvavadze, E. V., Osipova, I. M., and Panova, N. K.: Last Glacial Maximum climate of the former Soviet Union and Mongolia reconstructed from pollen and plant macrofossil data, Clim. Dyn. 15, 227-240, 1999.
Weber, S. L., Drijfhout, S. S., Abe-Ouchi, A., Crucifix, M., Eby, M., Ganopolski, A., Murakami, S., Otto-Bliesner, B., and Peltier, W. R.: The modern and glacial overturning circulation in the Atlantic ocean in PMIP coupled model simulations, Clim. Past, 3, 51-64, 2006, http://www.clim-past.net/3/51/2006/.

Wu, H., Guiot, J., Brewer, S., and Guo, Z.: Climatic changes in Eurasia and Africa at the Last Glacial Maximum and midHolocene: reconstruction from pollen data using inverse vegetation modelling, Clim. Dyn., 29, 211-229, doi:10.1007/s00382007-0231-3, 2007.

Wyputta, U. and McAvaney, B. J.: Influence of vegetation changes during the Last Glacial Maximum using the BMRC atmospheric general circulation model, Clim. Dyn., 17, 923-932, 2001. 